\title{
Nanoparticles Production and Inclusion in S. aureus Incubated with Polyurethane: An Electron Microscopy Analysis
}

\author{
Lyubov V. Didenko ${ }^{1}$, George A. Avtandilov ${ }^{2}$, Natalia V. Shevlyagina ${ }^{1}$, N. M. Shustrova ${ }^{1}$, \\ Tatiana A. Smirnova ${ }^{1}$, I. Y. Lebedenko ${ }^{2}$, Roberta Curia ${ }^{3}$, Claudio Savoia ${ }^{4}$, \\ Francesco Tatti ${ }^{5}$, Marziale Milani ${ }^{3 *}$ \\ ${ }^{1}$ Gamaleya Research Institute for Epidemiology and Microbiology, Gamaleya ul., Moscow, Russia \\ ${ }^{2}$ Moscow State Medical and Stomatological University, Moscow, Russia \\ ${ }^{3}$ Dipartimento di Scienza dei Materiali, Università degli Studi di Milano-Bicocca, Via Cozzi, Milano, Italy \\ ${ }^{4}$ ST Microelectronics, Via C. Olivetti, Agrate Brianza (Mi), Italy \\ ${ }^{5}$ FEI Italia, Viale Bianca Maria, Milano, Italy \\ Email: *marziale.milani@mater.unimib.it
}

Received April 23, 2013; revised May 21, 2013; accepted May 31, 2013

Copyright (C 2013 Lyubov V. Didenko et al. This is an open access article distributed under the Creative Commons Attribution License, which permits unrestricted use, distribution, and reproduction in any medium, provided the original work is properly cited.

\begin{abstract}
This study shows that submicron/nanoparticles found in bacterial cells (S. aureus) incubated with polyurethane (a material commonly used for prostheses in odontostomatology) are a consequence of biodestruction. The presence of polyurethane nanoparticles into bacterial vesicles suggests that the internalization process occurs through endocytosis. TEM and FIB/SEM are a suitable set of correlated instruments and techniques for this multi facet investigation: polyurethane particles influence the properties of $S$. aureus from the morpho-functional standpoint that may have undesirable effects on the human body. S. aureus and C. albicans are symbiotic microorganisms; it was observed that C. albicans has a similar interaction with polyurethane and an increment of the biodestruction capacity is expected by its mutual work with S. aureus.
\end{abstract}

Keywords: Polyurethane; S. aureus; Biodestruction; Endocytosis; FIB/SEM (Focused Ion Beam/Scanning Electron Microscope); TEM (Transmission Electron Microscope); STEM (Scanning Transmission Electron Microscope)

\section{Introduction}

The interaction of $S$. aureus with polyurethane is studied with electron and ion microscopy instrumentation (SEM, FIB and TEM). Biodestruction is a corrosion process of natural and artificial materials operated by microorganisms; it is remarkable for the polymeric materials commonly used in medicine, especially in orthopaedic stomatology where polyurethane occupies a special position [1-3].

Polyurethane dental prostheses have advantage over acrylic ones which provoke inflammatory reactions and intolerance when colonized by aggressive bacteria or fungi. In fact prostheses in the oral cavity are constantly attacked by microorganisms and their colonization often concurs in the destruction of the artificial materials. This

*Corresponding author. can lead to the release of allergenic substances, toxic to the human body [2,4-6].

A first approach to the investigation of polyurethane biodestruction was to understand how bacteria interact with the artificial material. Scanning Electron Microscope (SEM) was used to morphologically evaluate the damage induced by microorganisms (adherence, formation of microcolonies and biofilm) at different stages, depending on the exposure time of the material to the bacteria and on the state of the polyurethane surface. SEM observation revealed significant morphological changes of polymer surface due to bacteria activity: higher porosity, cracks and particles formation. Transmission Electron Microscope (TEM) was a complementary technique, useful to investigate the samples' inner structure and composition and to trace the pathway of polyurethane small particles (actually nanoparticles) while 
interacting with bacteria.

S. aureus is a permanent component of the microbial population in the oral cavity and it is considered a pathogen agent with biodestruction capacity. In fact staphylococci can adhere to the titanium and polymeric materials' (polyethylene) surfaces forming a mucoid matrix made up to $90 \%$ of water called biofilm $[7,8]$.

Staphylococci cause acute and chronic inflammation of soft tissues of the oral cavity (periodontal disease, sialodenity, gingivitis, etc) and they also influence the development of caries $[9,10]$. This may exacerbate chronic infectious processes and it can lead to the destruction of the prosthetic materials. In the presence of negative processes for the survival of microorganisms such as nutrients depletion, threat of drying, impact of chemical and physical factors in the external environment, bacteria can form biofilms [11]. The ability of bacteria to form biofilms is directly related to the increase of the biodestruction capacity [12].

\section{Materials and Methods}

Objects of the research were samples of polyurethane (Dentalur Russia). Various types of plastic surfaces (smooth, rough, surfaces resulted from sawing and splitting operations) were investigated.

Samples were analyzed in dual beam Focused Ion Beam/Scanning Electron Microscope (FIB/SEM) Quanta 200 3D (FEI Company, USA) in both high and low vacuum, mostly at $5 \mathrm{kV}$ electron beam acceleration [13-15].

The focused ion beam operated at low beam currents is used for imaging, at high beam currents is used for site specific in situ milling. The FIB/SEM investigation can be applied to bulk samples prepared for SEM analysis or to bulk resin-embedded specimens prepared for TEM observation. One of the FIB/SEM major advantages is that the operator may select his favourite site of investigation with less bonds than in TEM analysis.

TEM and STEM (Scanning Transmission Electron Microscope) images were acquired on a FEI TECNAI F20 X-TWIN, operated at $200 \mathrm{kV}$, equipped with a HAADF (High Angle Annular Dark Field) detector: STEM HAADF technique was preferred for the improved contrast and direct interpretation of the images.

Standard TEM images (Figure 2(a)) together with SEM ones show outside and inside the bacterial cells small dark particles that have higher density/mass than the $S$. aureus cell components and it is supposed that they are polyurethane nanoparticles. STEM (in TEM) images were produced by scanning the electron beam, focused in a very small spot, over the area of interest (like in a SEM) and collecting the electrons that came across the sample. One or more detectors collect the transmitted electrons, according to their scattering angle. A detector collects the very low angle electrons to form the so called Bright
Field (BF) images, whereas an annular detector collects the electrons scattered at higher angle to form Dark Field (DF) images. A third annular detector collects the electrons scattered at angles typically higher than $50 \mathrm{mrad}$ to form HAADF images. This last method allows direct interpretation of the images, being an imaging technique where the specimens' denser/heavier areas appear brighter in the final image.

The culture of $S$. aureus was isolated from a patient with a periodontal disease and incubated in broth with polyurethane. Control samples were a polyurethane slice with a smooth surface in broth and a broth with $S$. aureus without polyurethane. $\mathrm{pH}$ was checked after specimens incubation.

The incubation procedure is described in detail in ref.1 as well as samples preparation for TEM and SEM. Polyurethane samples and bacteria were incubated from 1 to 45 days at $37^{\circ} \mathrm{C}$. After centrifugation $(6000 \mathrm{rev} / \mathrm{min}$ for $10 \mathrm{~min}$ ) the bacterial pellet was placed on a silicon substrate for the FIB/SEM observation and prepared for the TEM analysis.

In samples preparation chemical-physical methods of dehydration were not applied in accordance to the traditional techniques, because standard drying operations leads to structural changes of biofilms and cells.

\section{Results}

Biocorrosion is a process that involves several steps from the material colonization to the formation of biofilms as discussed in ref.1.

Images obtained with FIB/SEM show that polyurethane undergoes biocorrosion by S. aureus (Figure 1).

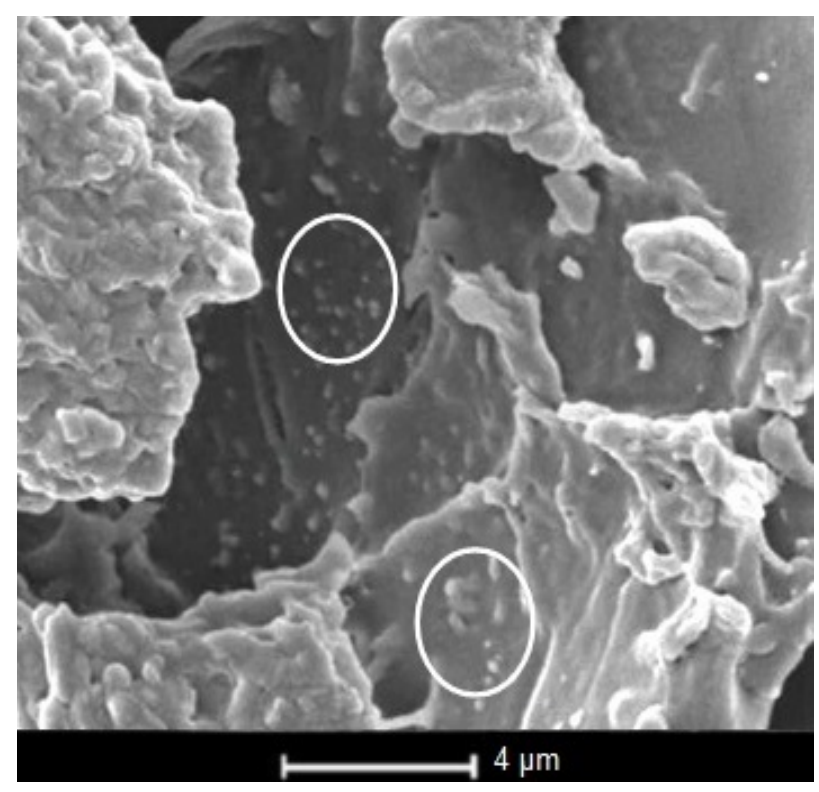

Figure 1. FIB/SEM electron image shows small particles of polyurethane (circles) on biofilm surface; this confirms that polyurethane undergoes biocorrosion by $S$. aureus. 
S. aureus is able to corrode surfaces of polyurethane generating particles of different size ranging from micrometers to nanometers as shown in Figure 2(a) (TEM image) and Figure 2(b) (STEM image). The same im-

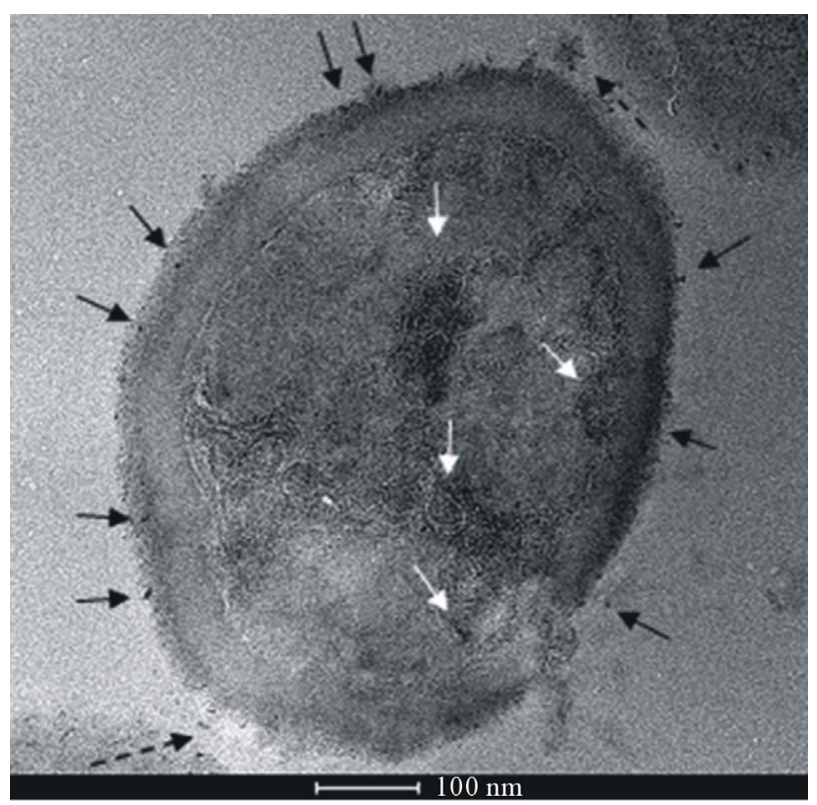

(a)

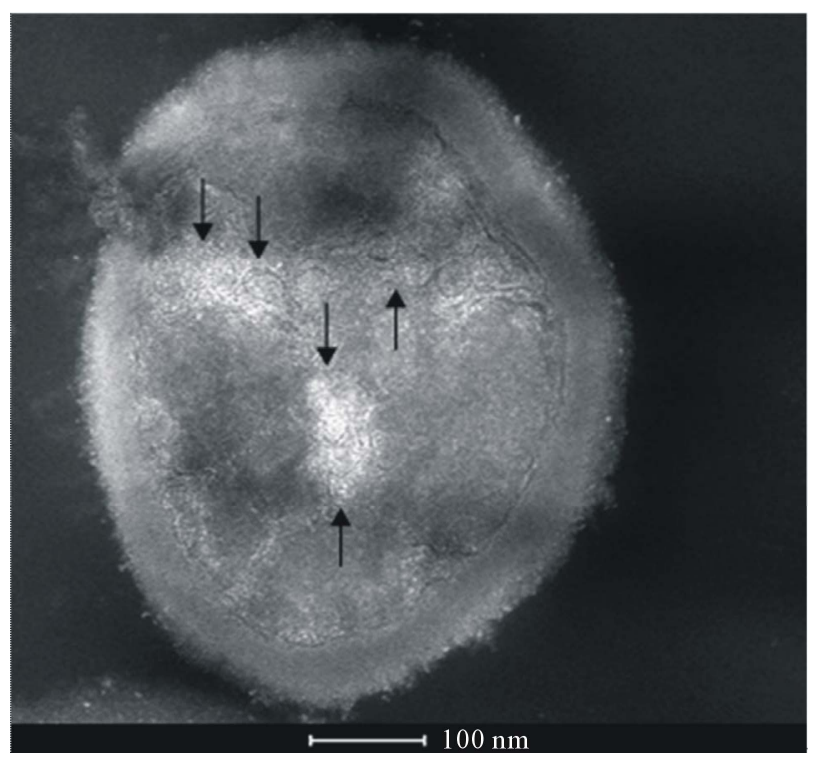

(b)

Figure 2. (a) TEM image of $S$. aureus after incubation with polyurethane. Polyurethane particles can be observed on the cell wall (black $\uparrow$ ), inside the cell surrounded by membranes (white $\uparrow$ ) and in the external environment, in the proximity of the cell wall (black dashed $\uparrow$ ); (b) STEM image of the same sample of (a) (rotated by $180^{\circ}$ ) in comparison to the TEM image. Polyurethane particles have higher electron density than the cell biological components, so they appear darker than the surrounding medium in TEM images and brighter in STEM ones. This image gives a better view of particles internalized into the cell $(\uparrow)$. ages show that $S$. aureus internalizes polyurethane nanometer sized particles.

Figure 3 (STEM- HAADF- image) shows circular membranous structures similar to vesicles inside $S$. aureus.

Figure 4 (STEM- HAADF- image) highlights the results of Figures 1-4 showing particles trapped in the pe-

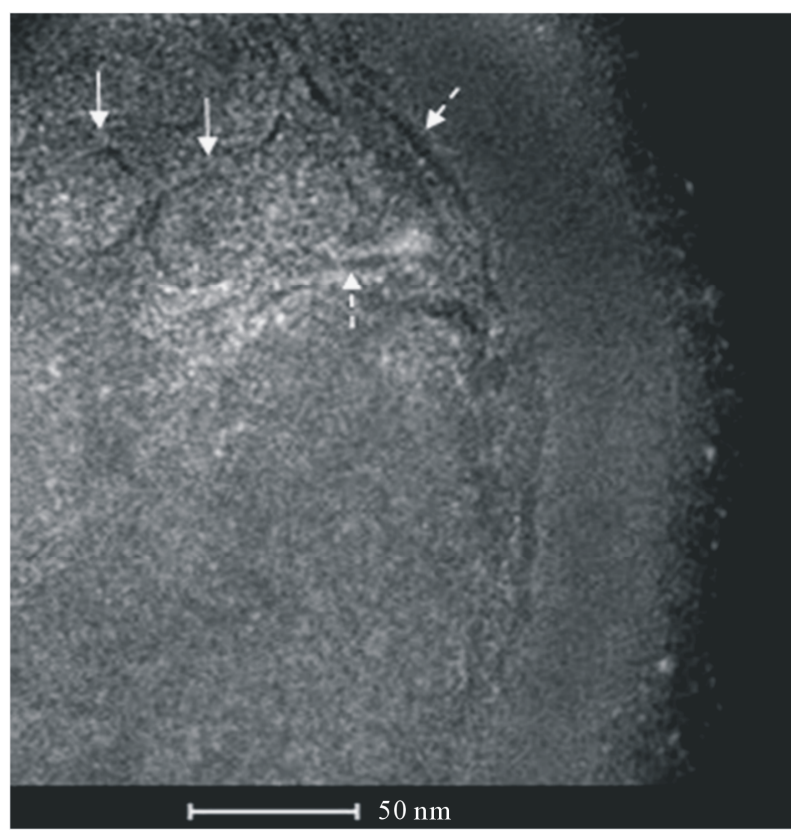

Figure 3. STEM image of $S$. aureus with round membranous structures similar to vesicles containing polyurethane particles $(\uparrow)$. Vesicles result from invaginations of the cytoplasmic membrane. Lysis of the cell wall is repaired after particles inclusion (dashed $\uparrow$ ).

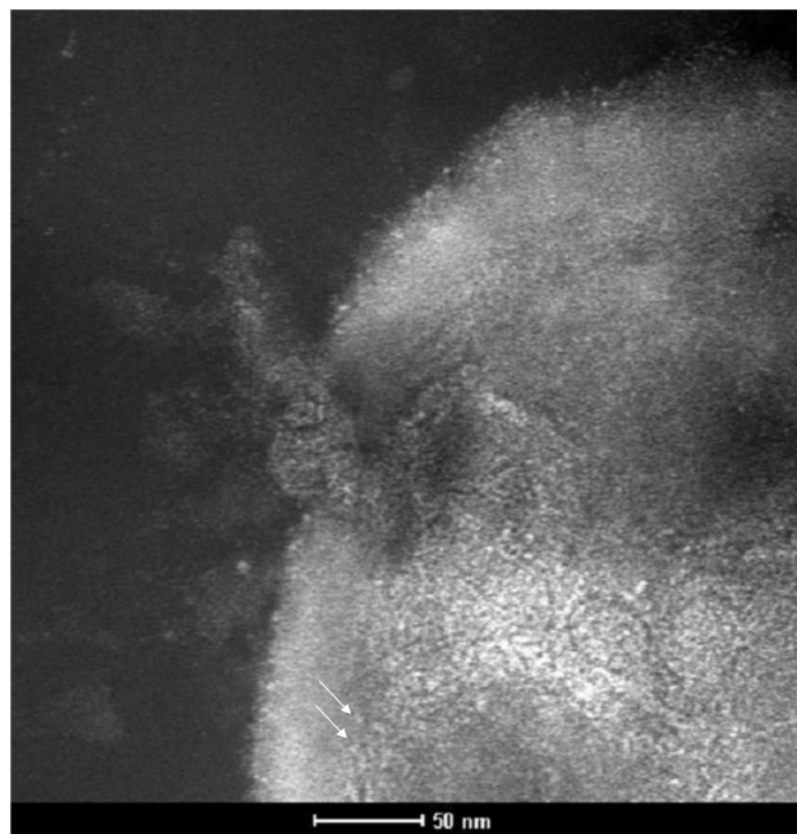

Figure 4. STEM image with particles localized in the peripla- mic space during the internalization process $(\uparrow)$. 
riplasm (space between the cytoplasmic membrane and the cell wall) during the internalization process.

\section{Conclusions}

1) The study shows structural evidence of the multisteps polyurethane biological degradation operated by $S$. aureus. Staphylococci metabolic activity increases the acid concentration with a negative impact on polymeric materials. The critical augmentation of bacterial mass causes nutrients depletion [11] forcing staphylococci to use plastic materials as an alternative source of nourishment. This is the starting point of biofilm formation.

2) S. aureus and C. albicans are symbiotic microorganisms; it was observed that C. albicans has a similar interaction with polyurethane and an increment of the biodestruction capacity is expected by its mutual work with S. aureus [16].

3) Formation of biofilm is accompanied by a size increment of the existing surface defects (as result of machining) and by the formation of new ones (large and fine particles of plastic material, cracks, ulcerations, caverns). Polyurethane surface under biofilm looks like lace.

4) The presence of polyurethane nanoparticles into bacterial vesicles suggests a process of endocytosis (a mechanism that allows the internalization of extracellular material through the invagination of the cytoplasmic membrane and the formation of vesicles containing foreign material). The absorption of the plastic material is clearly visible in the ultrafine slices of staphylococci, in the form of small grains on the cell wall, in the periplasm and in the cytoplasm.

5) The destruction of polymeric materials is accompanied by the release of substances which may cause allergic and toxic reactions in patients. Biofilm is the base for a long persistence of the pathogen agent that in turn causes chronic infectious processes of the oral cavity [17].

6) The presence of polyurethane nanoparticles into nomadic cells adds a further threat to the infection spread. Planktonic cells can die a natural death or an antibiotic induced one; which is the fate of internalized particles? Studies [18] report that nanoparticles can escape action from the immune system (phagocytosis by macrophages), enter the bloodstream and the lymphatic system, deposit themselves on organs and tissues and cause inflammation. The chapter on nanopathologies provoked by nanoparticles is still open and under investigation.

7) Ultrastructural data do not reveal bacterial death induced by the presence of nanoparticles as confirmed by the observation of cell fission testifying cells viability.

8) The vesicles could have been formed by endocytosis, a process that has been extensively studied in the eukaryotic domain, but has few experimental results in the bacterial one. A recent study [19] shows for the first time this type of mechanism into the bacterial domain using various techniques including transmission electron microscopy.

In conclusion electron microscopy [20] is an excellent and promising tool for the study of biocorrosion of polyurethane (FIB/SEM), biofilm characterization [21], research on nanoparticles inside the bacteria (TEM/ STEM) and endocytosis related processes.

\section{Acknowledgements}

Authors are indebted to Mauro Porcu for TEM analysis on Tecnai at FEI Nanoport in Eindhoven (NL) and for the useful discussion.

\section{REFERENCES}

[1] L. V. Didenko, G. A. Avtandilov, N. V. Shevlyagina, T. A. Smirnova, I. Y. Lebedenko, F. Tatti, C. Savoia, G. Evans and M. Milani, "Biodestruction of Polyurethane by Staphylococcus Aureus (an Investigation by SEM, TEM and FIB),” In: A. Méndez-Vilas, Ed., Current Microscopy Contributions to Advances in Science and Technology, Vol. 1, Formatex Research Center, Badajoz, 2012, pp. 323-334.

[2] G. A. Pkhakadze, "Morphological and Biochemical Aspects of Biodegradation of Polymers,” 1986.

[3] F. Cappitelli and C. Sorlini, "Microorganisms Attack Synthetic Polymers in Items Representing Our Cultural Heritage,” Applied Environmental Microbiology, Vol. 74, No. 3, 2008, pp. 564-569. doi:10.1128/AEM.01768-07

[4] Ya. V. Zachinyaev, I. I. Miroshnichenko and A. V. Zachinyaeva, "Microbial Degradation of Polyurethane," Russian Journal of Applied Chemistry, Vol. 82, No. 7, 2009, pp. 1321-1323. doi:10.1134/S1070427209070313

[5] J. A. Aas, B. J. Paster, L. N. Stokes, I. Olsen and F. E. Dewhirst, "Defining the Normal Bacterial Flora of the Oral Cavity,” Journal of Clinical Microbiology, Vol. 43, No. 11, 2005, pp. 5721-5732. doi:10.1128/JCM.43.11.5721-5732.2005

[6] M. Yu. Ogorodnikov, V. N. Tsaryov, R. Kh. Sulemova, "The Clinico-Microbiological Characterization of the Dynamics of the Microbial Colonization of Polyurethane and Acrylic Plastic-Based Removable Dental Prostheses," Ruskii Stomatological Journal, Vol. 83, No. 6, 2007, pp. 20-22.

[7] R. Bhola, S. M. Bhola, H. Liang and B. Mishra, "Biocompatible Denture Polymers-A Review," Trends in Biomaterials and Artificial Organs, Vol. 23, No. 3, 2010, pp. 129-136.

[8] G. T. Howard, "Biodegradation of Polyurethane: A Review,” International Biodeterioration \& Biodegradation, Vol. 49, No. 4, 2002, pp. 245-252.

[9] A. J. Smith, M. S. Jackson and J. Bagg, "The Ecology of Staphylococcus Species in the Oral Cavity,” Journal of Medical Microbiology, Vol. 50, No. 11, 2001, pp. 940946.

[10] A. D. Pye, D. E. A. Lockhart, M. P. Dawson, C. A. 
Murray and A. Y. Smith, “A Review of Dental Implants and Infection," Journal of hospital infection, Vol. 72, No. 2, 2009, pp. 104-110. doi:10.1016/j.jhin.2009.02.010

[11] C. G. Gemmell, "Coagulase-Negative Staphylococci," Journal of Medical Microbiology, Vol. 22, No. 4, 1986, pp. 285-295. doi:10.1099/00222615-22-4-285

[12] J. W. Costerton, R. T. Irvin, K.-J. Cheng and I. W. Sutherland, "The Role of Bacterial Surface Structures in Pathogenesis," Critical Reviews in Microbiology, Vol. 8, No. 4, 1981, pp. 303-338. doi:10.3109/10408418109085082

[13] M. D. Candia Carnevali and M. Milani, "Electron and Ion Microscopy and Micromanipulation: Common Principles and Advanced Methods in Applied Sciences," Proceedings of Summer School 2008 \& 2009, Esculapio, 8 September 2008-8 October 2008, pp. 129-186.

[14] M. Milani, D. Drobne and F. Tatti, "How to Study Biological Samples by FIB/SEM?” In: A. Méndez-Vilas and J. Díaz, Eds., Modern Research and Educational Topics in Microscopy, Formatex Research Center, Badajoz, 2007, pp. 787-794.

[15] M. Milani, D. Drobne and F. Tatti, "Atlas of FIB/SEM in Soft Materials and Life Sciences," Aracne Publishing, Rome, 2006.

[16] L. V. Didenko, G. A. Avtandilov, N. V. Shevlyagina, T. A. Smirnova, I. Y. Lebedenko, F. Tatti, C. Savoia, G.
Evans and M. Milani, "Biodestruction of Polyurethane by Staphylococcus Aureus (an Investigation by SEM, TEM and FIB),” FEI Dual Beam User-Club Meeting, Eindhoven, April 2012.

[17] C. Schaudinn, A. Gorur, D. Keller, P. P. Sedghizadeh and J. W. Costerton, "Periodontitis: An Archetypical Biofilm Disease," Journal of the American Dental Association, Vol. 140, No. 8, 2009, pp. 978-986.

[18] C. Buzea, I. I. Pacheco Blandino and K. Robbie, "Nanomaterials and Nanoparticles: Sources and Toxicity,” Biointerphases, Vol. 2, No. 4, 2007, pp. MR17-MR172. doi:10.1116/1.2815690

[19] A. Jermy, "Evolution: Bacterial Endocytosis Uncovered," Nature Reviews Microbiology, Vol. 8, No. 8, 2010, pp. 534-535. doi:10.1038/nrmicro2408

[20] J. R. McIntosh, "Electron Microscopy of Cells: A New Beginning for a New Century," The Journal of Cell Biology, Vol. 153, No. 6, 2001, pp. F25-F32. doi:10.1083/jcb.153.6.F25

[21] P. K. Wallace, B. Arey and W. F. Mahaffee, "Subsurface Examination of a Foliar Biofilm Using Scanning Electron- and Focused-Ion-Beam Microscopy," Micron, Vol. 42, No. 6, 2011, pp. 579-585. doi:10.1016/j.micron.2011.02.003 